\title{
PELAKSANAAN KURIKULUM 2013 DALAM PEMBELAJARAN PPKn DI SMA AL HUSNA KEDAUNG
}

\author{
Lina Marlina1, Siti Khamroh ${ }^{2}$ \\ ${ }^{12}$ Universitas Banten \\ Serang, Indonesia \\ linamarlina@unbaja.ac.id ${ }^{1}, \underline{\text { sitikhamroh@gmail.com }}^{2}$
}

\begin{abstract}
Implementation of the 2013 curriculum at SMA Al Husna Kedaung in 2015. With the regulation of the minister of education and culture regarding the implementation or implementation of the 2013 curriculum in elementary and senior high schools, the curriculum has been implemented in a many areas. Al Husna Kedaung High School is trying as much as possible in order to make the regulations of the Minister of Education and Culture successful and to realize national goals. (1) To find out the Implementation of the 2013 Curriculum in PPKn Learning at SMA Al Husna Kedaung.(2) To find out what are the teacher's obstacles in implementing 2013 Curriculum in Civics Learning at Al Husna Kedaung High School. (3) To find out the teacher's efforts in overcoming the obstacles to implementing the 2013 curriculum in Civics learning at SMA Al Husna Kedaung. To achieve this goal, the researchers used data collection techniques through observation, interviews and documentation. The data that has been obtained from the research results are processed using qualitative descriptive analysis with primary data as many as 2 PPKn subject teachers at SMA Kedaung. The results of the study on the Implementation of the 2013 Curriculum for Civics in SMA Al Husna Kedaung showed that: (1) Implementation of the 2013 Curriculum for Civics subjects at SMA Al Husna Kedaung had not run effectively because some teachers had not mastered the 2013 curriculum in the form of lesson plans, syllabus, KI-KD, prota, prosem, indicators, learning methods, learning strategies, learning approaches and assessment of learning outcomes. (2) Obstacles experienced by teachers in implementing the 2013 curriculum for Civics subjects at Al Husa Kedaung High School. (3) The efforts made by PPKn teachers in overcoming the obstacles faced in implementing the 2013 curriculum are: Implementation of the 2013 curriculum at Al Husna Kedaung High School, by the 2013 curriculum guidelines.
\end{abstract}

Keywords: Implementation, 2013 curriculum, Pancasila and Citizenship Education

\section{PENDAHULUAN}

Kurikulum 2013 adalah kurikulum yang menekankan pada pendidikan karakter, terutama pada tingkat dasar yang akan menjadi fondasi pada tingkat berikutnya. melalui pengembangan kurikulum 2013 yang berbasis karakter dan berbasis kompetensi kita berharap bangsa ini menjadi bangsa yang memiliki nilai jual yang bisa ditawarkan kepada bangsa lain didunia. Menurut (Mulyasa, 2014 dalam Muhammad syahroi, dkk, 2015:4). Kurikulum 2013 yaitu kurikulum berbasis kompetensi yang merupakan konsep kurikulum yang menitik beratkan pada pengembangan karakter dan kemampuan melakukan (kompetensi) tugastugas dengan ketentuan standar tertentu, sehingga hasilnya dapat dirasakan oleh siswa, seperti penguasaan terhadap kompetensi, materi tertentu. Sesuai dengan konteks yang sebenarnya, mengajar mengandung banyak tindakan, baik mencakup teknis penyampaian materi, penggunaan metode pembelajaran, penggunaan media pembelajaran, 
membimbing belajar, memberi motivasi, mengelola kelas, memberikan penilaian dan seterusnya. Mengajar itu sangatlah kompleks, yakni terdiri dari berbagai komponen pembelajaran. (Ardi, 2014 dalam Lina Marlina, dkk, 2021) Tidak hanya berbasis pada kompetensi, hal terpenting dalam penerapan Kurikulum 2013 adalah penerapan pendidikan karakter.(perdomuan NJM Sinambela, dalam Otang Kurniawan dkk, 2017:5)

Istilah kurikulum muncul untuk pertama kalinya dan digunakan dalam bidang olahraga. secara etimologis curriculum yang berasal dari yunani, yaitu curir yang artinya "pelari" dan curere yang berart "tempat berpacu". Jadi istilah kurikulum pada zaman romawi kuno mengandung pengertian sebagai suatu jarak yang harus ditempuh oleh pelari dari garis start sampai garis finish baru pada tahun 1855 , istilah kurikulum dipakai dalam bidang pendidikan yang mengandung arti sejumlah mata pelajaran pda perguruan tinggi.

Dalam kamus Webster kurikulum diartikan dalam dua macam, yaitu:

a. Sejumlah mata pembelajaran yang harus ditempuh atau di pelajari mueid di sekolah atau perguruan tinggi untuk memperoleh ijazah tertentu.

b. Sejumlah mata pelajran yang ditawarkan oleh suatu lembaga pendidikan atau departemen

Dalam pandangan klasik kurikulum dipandang sebagai rencana pembelajaran di suatu sekolah suatu sekolah atau madrasah. Pelajaran-pelajaran dan materi apa harus ditempuh di sekolah atas madrasah, itulah kurikulum. (Menurut Sholeh hidayat, 2017:19-20). Menyatakanbahwa kewarganegaraan merupakan materi yang memfokusk pada pembentukan diri yang beragam, baik dari segi agama, sosiokultural, bahasa, usia, dan suku bangsa, untuk menjadi warga negara Indonesia yang cerdas, terampil, dan berkarakter. Dengan demikian, Pendidikan

Pancasila dan Kewarganegaraan (PPKn) merupakan mata pelajaran yang memfokuskan pada pembentukan warga negara yang memahami dan mampu melaksanakan hakhak dan kewajibannya untuk menjadi warga negara Indonesia yang cerdas, terampil, dan berkarakter yang diamanatkan oleh Pancasila dan UUD 1945. (Aryani dan Susantim 2010:11 dalam Endang Yulianti,dkk 2020:2).

Awal pelaksanaan Kurikulum 2013 mengalami banyak kendala, dari guru, yang sebagian besar belum memiliki pendidikan minimal yang dipersyaratkan, disamping penyebaran yang tidak seimbang antar sekolah dan antar daerah. Permasalahan tersebut lebih dipersulit lagi dengan kenyataan guru yang mengajar tidak sesuai dengan bidang keahliannya. tenaga pendidik 
yang kurang siap, penyesuaian siswa terhadap pergantian kurikulum baru yang cukup membutuhkan waktu, belum adanya buku guru dan buku siswa yang sesuai dengan Kurikulum 2013 revisi 2017, serta aspek penilaian Kurikulum 2013 banyak dan cukup rumit. Kurikulum 2013 di SMA Al Husna Kedaung dalam pelaksanaanya masih mengalami kendala karena penyesuaian terhadap perubahan kurikulum baru. Dengan adanya peraturan mentri pendidikan dan kebudayaan tentang pelaksanaan atau penerapan kurikulum 2013 di sekolah dasar dan menengah, di sejumlah daerah telah diterapkan kurikulum tersebut. Meskipun banyak sekolah dan guru yang tidak siap menerapkan kurikulum 2013 tetapi SMA Al Husna desa kedaung berusaha menerapkan kurikulum tersebut dengan maksimal. SMA Al Husna kedaung berusaha semaksimal mungkin dalam rangka mengsukseskan peraturan permendikbud serta mewujudkan tujuan nasional.

\section{METODE PENELITIAN}

Metode yang digunakan dalam penelitian ini yaitu metode penelitian deskriptif dengan menggunakan pendekatan kualitatif. Penelitian kualitatif dilaksanakan untuk membangun pengetahuan melalui pemahaman dan penemuan. Penelitian kualitatif adalah suatu proses penelitian dan pemahaman yang berdasarkan pada metode yang menyelidiki suatu fenomena social dan masalah manusia. Pada penelitian ini peneliti membuat suatu gambaran kompleks, meneliti kata-kata, laporan terinci dari pandagan responden dan melakukan studi pada situasi yang alami.metode kualitatif adalah "prosedur penelitian yang menghasilkan data dekskriptif, yang berupa kata-kata tertulis atau lisan dari orang-orang dan perilaku yang diamati”.Menurut Bog dan Taylor dalam Moleong (2014:4)

Pendekatan penelitian kualitatif Menurut (Sugiyono 2015:15) adalah metode penelitian yang berlandaskan pada filsafat postpositifisme, digunakan untuk meneliti pada kondisi obyek alamiah, (sebagai lawannya eksperimen) dimana peneliti adalah sebagai instrument kunci, Teknik pengumpulan data dapat dilakukan induktif/kualitatif, dan hasil penelitian kualitatif lebih menekankan makna dari pada generalisasi.

\begin{tabular}{ccc}
\hline secara & triangulasi & (gabungan), \\
\hline analisis & data & bersifat \\
\hline
\end{tabular}

Penelitian yang digunakan dalam penelitian ini adalah penelitian deskriptif kualitatif (Moleong 2014:28) yang menjelaskan kejadian atau fakta, keadaan dan fenomena yang terjadi dilapangan.

Peneliti menggunakan penelitian ini bertujuan untuk menggambarkan dan menjelaskan kejadian yang ada atau fakta dan fenomena yang terjadi di lapangan mengenai pelaksanaan kurikulum 2013 
mata pelajaran PPKn di SMA Al Husna Kedaung.

\section{HASIL TEMUAN PENELITIAN DAN PEMBAHASAN}

Hasil temuan penelitian ini diperoleh berdasarkan prosedur pengumpulan data yang telah dilakukan oleh peneliti. Adapun yang menjadi sumber data untuk melakukan pengkajian tentang Pelaksanaan Kurikulum 2013. Dalam Pembelajaran PPKn Di SMA Al Husna Kedaung jln KH. UmarDesa Kedaung Kp. Rencalang Kecamatan Mekar Baru Kab Tangerang, yaitu obsrvasi, wawancara dan dokumentasi Observasi

a. Pelaksanaan kurikulum 2013 dalam pembelajaran PPKn di SMA AL HUSNA Kedaung

Kurikulum 2013 adalah kurikulum yang menjadi acuan pelaksanaan pembelajaran di sekolah/madrasah, dari mulai tingkat pendidikan dasar sampai tingkat

\begin{tabular}{lcr}
\hline pendidikan & menengah. & Kebijakan \\
\hline tentang & kurikulum & 2013. \\
\hline
\end{tabular}

Berdasarkan pengamatan secara langsung kepada guru PPKn di SMA Al Husna Kedaung, maka pelaksanaan kurikulum 2013 dalam pembelajaran PPKn di SMA Al Husna Kedaung adalah sebagai berikut : pendahuluan, isi dan penutup. Sesuai dengan kurikulum
2013.

Kurikulum 2013 dibuat dengan komposisi yang seimbang antara softskill dan hardskill. Hal ini dapat dilihat langsung dari pola pikir rumusan kurikulum yang ada. Misalnya untuk Standar Kompetensi Lulusan lebih diturunkan dari kebutuhan dan semua pembelajaran harus dapat memberikan kontribusi yang nyata untuk sikap dan pengetahuan peserta didik, berdasarkan hasil temuan di SMA Al HUSNA Kedaung bahwa pelaksanaan kurikulum 2013 telah menerapkan konsep kurikulum tersebut, diamana dalam pelaksanaan pembelajarannya adanya SKL dalam pembelajarannya, sehingga peserta didik dapat memenuhi nilai-nilai yang ada pada kompetensi lulusan tersebut. Hambatan Guru dalampembelajaran PPKn di SMA Al Husna Kedaung.

Berdasarkan hasil observasi, adapun hambatan-hambatan yang dialami oleh guru dalam pelaksanaan kurikulum 2013 ialah factor internal dan factor eksternal.

1) Adapun factor internal sebagai berikut: factor berasal dari diri siswa dan factor dari guru.

a) Factor dari diri siswa : dimana peneliti melihat kurang semangat dalam belajar ketika guru menjelaskan. Masih ada siswa yang tertidur di dalam kelas ketika jam pelajaran berlangsung, bermain Hp dan mengbrol.

b) Factor dari guru : hambatan- 
hambatan dari guru antara lain: kurangnya fasilitas yang memadahi untuk pembelajaran yang menunjang siswa dan menanamkan nilai moral dalam diri siswa.

2) Factor eksternal: factor yang mempengaruhi dalam pembelajarannya kurangnya sarana dan prasarana misalnya penunjang belajar seperti proyektor,dan computer untuk menunjang pembelajaran ketika meterinya menggunakan media audio visual itu sendiri.

\section{PEMBAHASAN}

Data hasil penelitian yang telah dilakukan maka data yang diperoleh sebagai berikut : observasi, wawancara, dan dokumentasi. Dari penelitian diatas dapat dijelaskan sebagai berikut:

\section{Pelaksanaan kurikulum 2013 dalam pembelajaran PPKn di SMA AL Husna}

\section{Kedaung.}

Langkah-langkah yang harus dilakukan oleh guru dalam proses pembelajaran berbasis K-13 (Permendikbud No. 81a Tahun 2013). Adapun langkah-langkahnya adalah sebagai berikut :

a. Kegiatan Awal

Dalam Kurikulum K-13 langkah yang pertama yang harus dilakukan oleh seorang guru adalah pembukaan.
Dari penelitian di kelas SMA Al HUSNA, pada kegiatan awal ini guru melakukan pembukan dengan melakukan $5 \mathrm{~S}$, senyum, salam, sapa, sopan dan santun, melakukan do'a terlebih dahulu, memberikan penghantar materi yang akan di sampaikan saat pembelajaran dan membangkitkan motivasi belajar siswa.

b. Kegiatan Inti

Mengamati adalah proses awal dari serangkaian tahapan pembelajaran yang berpusat pada siswa. Dalam proses mengamati ini diharapkan dapat melatih dalam hal kesungguhan dan ketelitian dalam mencari sebuah informasi. Dalam kegiatan mengamati, guru membuka secara luas dan bervariasi kesempatan peserta didik untuk melakukan pengamatan melalui kegiatan : melihat, menyimak, mendengar dan membaca yang diformulasikan pada sekenario proses pembelajaran. Dari hasil penelitian di sekolah SMA AL HUSNA KEDAUNG ini, guru melakukan kegiatan inti ini dengan memberikan dari salah satu kegiatan inti tersebut guru mengamati dalam yang ada pada sumber buku tersebut siswa 
memberikan pengamatannya.

c. Kegiatan akhir

Pada kegiatan penutup ini guru memberikan simpulan dari apa yang sudah dipelajari pada hari itu, memberikan motivasi akhir, memberikan pengayaan, serta memberikan salam dan berdo'a bersama Dari hasil penelitian ini peneliti melihat bahwa guru dalam kegiatan akhir ini memberikan pertanyaan dan kesimpulan di akhir pembelajaran berlangsung

\section{Hambatan Guru dalam pembelajaran PPKn di SMA Al Husna Kedaung}

Sarana dan Prasarana Pelaksanaan pendidikan nasional harus menjamin pemerataan dan peningkatan mutu pendidikan di tengah perubahan global agar warga Indonesia menjadi manusia yang bertakwa kepada Tuhan Yang Maha Esa, berakhlak mulia, cerdas, produktif, dan berdaya saing tinggi dalam pergaulan nasional maupun internasional. Untuk menjamin tercapainya tujuan pendidikan tersebut, Pemerintah telah mengamanatkan penyusunan delapan standar nasional pendidikan sebagaimana diatur dalam Peraturan Pemerintah Republik Indonesia No. 19 Tahun 2005 tentang Standar Nasional Pendidikan.

Upaya guru dalam mengatasi hambatan pelaksanaan kurikulum 2013 dalam pembelajaran PPKn di SMA Al

\section{Husna Kedaung}

Secara umum upaya yang dilakukan guru untuk mengatasi kendala yang dihadapi dalam pelaksanaan kurikulum 2013 mata pelajaran PPKn di SMA Al Husna Kedaung yaitu guru perlu mengikuti pelatihan MGMP tingkat kabupaten kota dan pendampingan kurikulum 2013, sehingga guru bisa mempelajari materi-materi atau komponen kurikulum 2013 yang belum dipahami termasuk didalam nya ada 13 item seperti RPP, Silabus, Prota, Promes sampai pada teknik penilaian sesuai kurikulum 2013.

\section{KESIMPULAN}

Berdasarkan hasil temuan dan pembahasan dalam bab IV, maka diajukan kesimpulan sebagai berikut :

1. Pelaksanaan kurikulum 2013 di SMA Al Husna Kedaung, sesuai dengan pedoman kurikulum 2013 ialah konsep kurikulum, kompetensi inti dan kompetensi dasar, rencana pelaksanaan pembelajaran PPKn di SMA Al Husna Kedaung sesuai dengan pemndikbud 81 A ialah pendahuluan (kegiatan awal), isi (kegiatan inti) dan Penutup (kegiatan akhir)

2. Hambatan pelaksanaan kurikulum 2013 dalam pembelajaran PPKn di SMA Al Husna Kedaung, ada 2 yang menghambat dalam pelaksanaan kurikulum tersbut yang pertama dari pemerintah dan factor dari guru tesbut, 
factor pemerintah mempengaruhi dalam proses pembelajran Adanya materi yang tidak sesuai dengan konsep yang ada harus disikapi dengan pembetulan konsep agar tidak terjadi miskonsepsi pada siswa. Tata urutan materi tidak harus sesuai dengan yang ada di Buku Siswa, Buku Guru, maupun silabus. Guru harus mengurutkan materi sesuai urutan logis materi tersebut. Dan yang kedua hambatan dafi guru yaitu Semua guru harus di berdayakan dan dituntut harus paham tentang substansi kurikulum dan penerapannya dalam proses pembelajaran. Kunci keberhasilan suatu pendidikan terletak pada kualitas guru

dan profesionalisme guru, meskipun sekarang teknologi sudah canggih dan menjadi bagian tidak terpisahkan dalam dunia pendidikan.

3. Upaya yang dialami Guru Dalam Perencanaan Pembelajaran, Pelaksanaan Pembelajaran Mata Pelajaran PPKn di SMA Al Husna Kedaung Upaya yang dilakukan guru mata pelajaran PPKn di SMA Al Husna Kedaung dalam mengatasi hambatan dalam pelaksanaan pembelajaran diantaranya guru discovery learning dimana peserta didik harus meneliti dan mencari informasi terkait materi pembelajaran dan juga siswa harus aktif dalam kegiatan diskusi, namun dalam hal ini guru tidak melepas siswa begitu saja melainkan tetap membimbing dengan cara menggabungkan metode lama yaitu metode ceramah oleh guru mata pelajaran PPKn sesuai kurikulum 2013.

\section{DAFTAR PUSTAKA}

Hidayat sholeh. (2017). Pengembangan Kurikulum Baru. Bandung : PT Remaja Rosdakarya.

J. Moleong, Lexy. (2014). Metode Penelitian Kualitatif. Edisi Revisi. PT Rosdakarya, Bandung

Marlina.,Lina.dkk. (2021) Penerapan Pembelajaran Blended Learning Pada Mahasiswa Semeter 6 Mata Kuliah Pplk 1 Program Studi PPKn, PRO PATRIA: Jurnal Pendidikan, Kewarganegaraan, Hukum, Sosial dan Politik, Vol 4 No 2 (2021) pada laman web: http://ejournal.lppmunbaja.ac.id/index.php/propatria/artic le/view/1419

Sugiyono. (2017). Metode Penelitian Kualitatif, dam R\&D. Bandung : Alfabeta, CV

Suyono, Hariyanto. (2011). Belajar dan Pembelajaran. Bandung : PT Remaja Rosdakarya.

Mahasiswa Fakultas Keguruan dan Ilmu Pendidikan Universitas Riau.Volume 2. Halaman 1-8 (Abdullah Sani, 2013:131-132 dalam Lina Marlina dkk 2018:2) 
Mulyasa, 2014:6 dalam Muhammad syahroi, dkk, 2015:4) Implemntasi Kurikulum $2013 \quad$ Dalam Pembelajaran PPKn Di SMA Negri Sekota Pekanbaru. Jurnal Online

\section{UNDANG-UNDANG}

Peraturan Kementrian Pendidikan Nasional Republik Indonesia Nomor 81 A Tahun 2013

(perdomuan NJM Sinambela, dalam

Otang Kurniawan dkk, 2017:5)

(Aryani dan Susantim 2010:11 dalam Endang Yulianti,dkk 2020:2)

Muzamiroh Latifatul Mida, 2013:5 dalam Syahroi Muhammad, dkk 2015:7, Implemntasi Kurikulum 2013 Dalam Pembelajaran PPKn Di SMA Negri Sekota

Pekanbaru.Jurnal Online

Mahasiswa Fakultas Keguruan dan

Ilmu Pendidikan Universitas

Riau.Volume 2. Halaman 1-8

Undang-Undang No. 20 Tahun 2003

Tentang Sistem Pendidikan

Nasional 
